\title{
DEVELOPMENT OF AN ENERGY AUDIT WORKING PROCEDURE FOR AN ACADEMIC UNIVERSITY OFFICE BUILDING IN THE PHILIPPINES
}

\author{
Maxine Chan, Emmanuel Arriola, Reynaldo Cuevas III, and Joseph Gerard Reyes \\ Energy Engineering Program, College of Engineering, University of the Philippines Diliman, \\ Quezon City, Philippines, Tel: +63 9177261868, e-mail: maxineychan@gmail.com, erarriola@ outlook.com, \\ reycuevasiii@gmail.com,jtreyes2@up.edu.ph
}

Received Date: February 24, 2020; Revised Date: September 14, 2020; Acceptance Date: October 12, 2020

\begin{abstract}
The Philippine commercial building sector accounts for roughly $10 \%$ of the total electricity power consumption. For this research, an energy audit was conducted in an academic office building of a Philippine university. The study focused on eight representative offices within the building to serve as pilot facilities for this research. The study evaluated the performance of existing lighting fixtures to attain the minimum acceptable standard of 300 lux for offices as well as the performance of existing air conditioning units to achieve a recommended room temperature of 24 Celsius. From the results, it is evident that the air conditioning unit makes up majority of energy use in almost all offices, with an average of $63 \%$ of total power consumption, followed by lights with $23 \%$ and plugin loads with $14 \%$. For maximum lux values with minimal energy consumption, the use of LED lights is recommended while for temperature, the use of inverter technology is encouraged for long term energy savings.
\end{abstract}

Keywords: Commercial building, Energy audit, Lux, Power consumption, Room temperature

\section{Introduction}

The Philippine commercial building sector is one of the more energy-intensive players in the national grid, accounting for roughly $10 \%$ of the total electricity power consumption [1]. Because of this, implementing energy efficiency measures is highly encouraged through technological and behavioural measures. To be considered energy efficient, one must consider minimizing energy consumption while maintaining standard working conditions for worker productivity and health.

Within the main academic university office building, eight (8) representative offices were chosen to serve as pilot facilities, namely the Administration Office, Building Research Service (BRS), Engineering Information Services (EIS), Executive Director's Office, Printing Office, Professional Engineering Training Division (PETD), Project Management Office (PMO), and the UP Alumni Engineers Office (UPAE). Table 1 lists the representative offices and their corresponding functions. These offices were chosen due to their varied functions across the academic university office building, thus they would provide a wider representation of office energy consumption profiles. Likewise, these offices were under the direct administration of the university, hence, performance of the study was allowed.

The main objective of the study is to maximize efficiency of electricity usage within the eight offices. Specifically, it aims to evaluate the performance of existing lighting fixtures to attain the minimum acceptable standard of 300 lux for offices [2]. Another goal 
of this study is to evaluate the performance of existing air conditioning units to achieve a recommended room temperature of 24 Celsius. The range of values is higher than standard room temperature since the audit period of the project is within the summer season, thus entailing a higher outdoor temperature. As to appropriately check for air conditioning unit efficiency, the range of ambient temperature is set higher to fit the tropical climate of the Philippine environment [3]. Lastly, the project plans to look into the electricity consumption of the other equipment within the offices.

Table 1. Offices and Their Corresponding Functions

\begin{tabular}{|c|c|}
\hline Office & Function \\
\hline Administration Office & $\begin{array}{l}\text { Responsible for financial planning, record } \\
\text { keeping \& billing, personnel, physical } \\
\text { distribution and logistics }\end{array}$ \\
\hline Building Research Services (BRS) & $\begin{array}{l}\text { Fosters and undertake integrated research, } \\
\text { advisory and information dissemination in } \\
\text { building and housing in the Philippines }\end{array}$ \\
\hline Engineering Information Services (EIS) & $\begin{array}{l}\text { Supports engineering campus } \\
\text { initiatives and provides vital enterprise data }\end{array}$ \\
\hline Executive Office & $\begin{array}{l}\text { In charge of designing, developing and } \\
\text { implementing strategic plans for the } \\
\text { engineering research arm of the university }\end{array}$ \\
\hline Printing Office & $\begin{array}{l}\text { Serves as the printing center for the entire } \\
\text { academic university office building }\end{array}$ \\
\hline $\begin{array}{c}\text { Professional Engineering Training } \\
\text { Division (PETD) }\end{array}$ & $\begin{array}{l}\text { Handles training and development as a } \\
\text { function concerned with organizational }\end{array}$ \\
\hline & $\begin{array}{c}\text { activity aimed at improving the job } \\
\text { performance of individuals and groups in } \\
\text { engineering }\end{array}$ \\
\hline Project Management Office (PMO) & $\begin{array}{l}\text { Different research project teams of the } \\
\text { academic university use this room as their }\end{array}$ \\
\hline UP Alumni Engineers Office (UPAE) & $\begin{array}{l}\text { Used for Engineering graduates in } \\
\text { professional matters of collective interest, as } \\
\text { well as be of service to its alumni }\end{array}$ \\
\hline
\end{tabular}

Energy modelling software is oftentimes used when it comes to analysing building energy efficiency. A research was conducted in a school cafeteria to see which components contribute the largest share on overall power consumption. The study used the Visual DOE 4.1 software which required input parameters such as building shell, operation schedules, and systems such as lighting and air-conditioning. From the results, the cooling system made up around $66 \%$ of electricity used, followed by lighting and fans [4]. Though the study was able to determine the significant factors, the procedure in obtaining the power densities was not mentioned. In terms of validating the model inputs, the energy audit procedure mentioned the collection of bills but not the actual collection of power measurements, particularly the cooling units which can be prone to a higher actual energy use as the system ages. A study on energy consumption patterns of a library was conducted and one of the findings illustrated how the air-conditioning units (ACU) had a higher measured power reading compared to the rated values, given the age of the units [5]. In order to obtain a wider estimate for overall building energy consumption, this study looked into eight office spaces while monitoring 
their respective working environments based on lighting and temperature. The study, however did not utilize the energy use intensity (EUI) values in formulating its baseline, which are determined by obtaining $\mathrm{kWh}$ consumption over the floor area of the facility.

According to a research paper conducted by the Riga Technical University in Latvia, indoor temperature and relative humidity have an impact when it comes to energy efficiency in office buildings, however this utilized the recommended indoor air parameters from European standards and not measurements from an actual building sample [6]. In order to assess thermal comfort within the Mediterranean climate, another study used a university office building, which was equipped with measurement devices to analyse the ambient comfort of the occupants. Aside from this, a survey was administered in order to gather the perspectives of the occupants in the building [7]. In this case however, the building is a one storey, house-like structure, with only two rooms. Aside from this, the temperature was only monitored based on the entire floor area and was not divided into smaller sections, wherein it is possible for some spots to be warmer/cooler.

With these studies taken into consideration, this research would highlight the energy audit procedure which would serve as a basis for creating an Energy Efficiency Index (EEI) as a baseline. The EEI sets the minimum efficiency requirement for the normal operation conditions of the offices and establishes a gauge for performance evaluation. Given this, proposed alternatives can be compared to the baseline to analyze possible energy saving solutions.

\section{Methodology}

The study commenced with an initial meeting with the people in charge of the respective offices wherein the proponents were given an overview of the operation of the office. During the initial meeting, an ocular inspection was also conducted wherein measurements of the area were obtained. Afterwards, data such as the floor plan and the equipment specifications were gathered from the pre-audit. The pre-audit also served as an initial assessment on how to conduct the actual audit and measurement of pertinent data. In the actual energy audit the following data were collected: lux level (lux), ambient temperature $\left({ }^{\circ} \mathrm{C}\right)$, outdoor temperature, and energy consumption $(\mathrm{kWh})$ of the lighting, ACU, and office equipment. Apart from this, the number of occupants per office were also obtained. Afterwards, the collected data were analyzed; consequently, recommendations were given and evaluated. From the evaluation of recommendations, the conclusion was formulated. Figure 1 shows the general process flow for the entire work procedure.
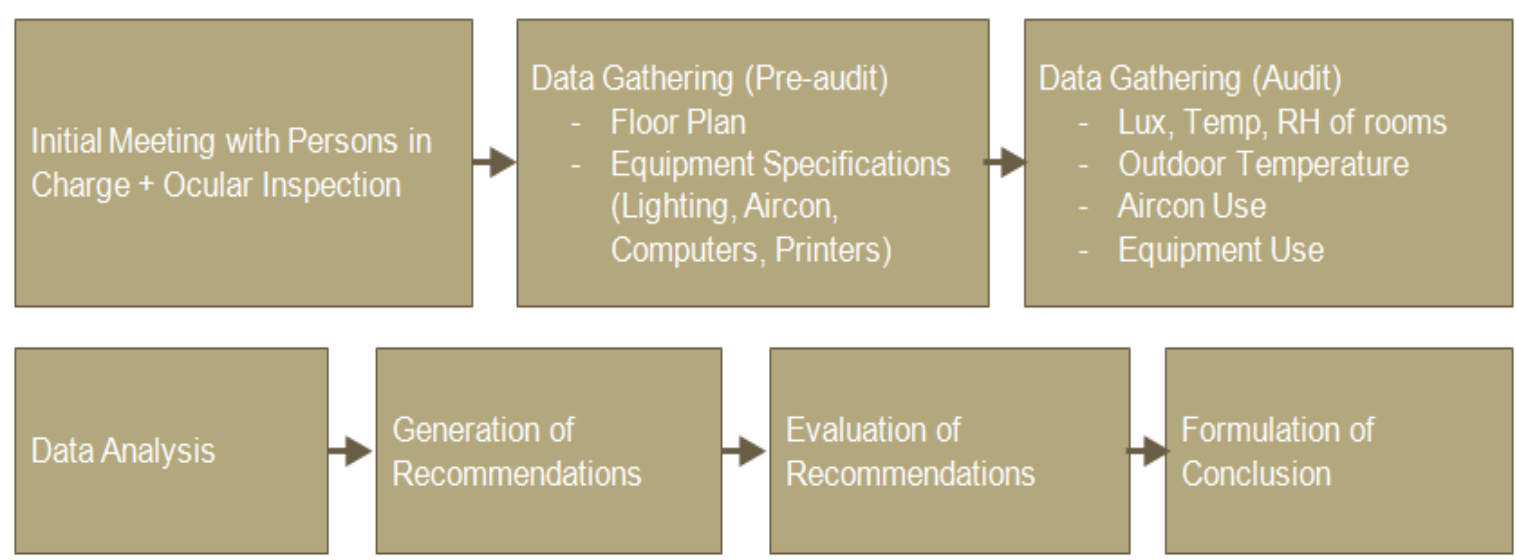

Figure 1. Work procedure for energy audit for academic university office building 
Each of the offices was divided into $2 \mathrm{~m}$ by $2 \mathrm{~m}$ grids in order to perform localized temperature and lighting level measurements per zone. The light intensity was measured using a lux meter; positioning the instrument at approximately 0.75 meters from ground level, while the temperature was measured using a thermocouple at a level where the ambient temperature can be sensed by room occupants. These were done in order to identify spot problem areas that are too cold/hot and too bright/dark. Figure 2 below illustrates the zoning division procedure.

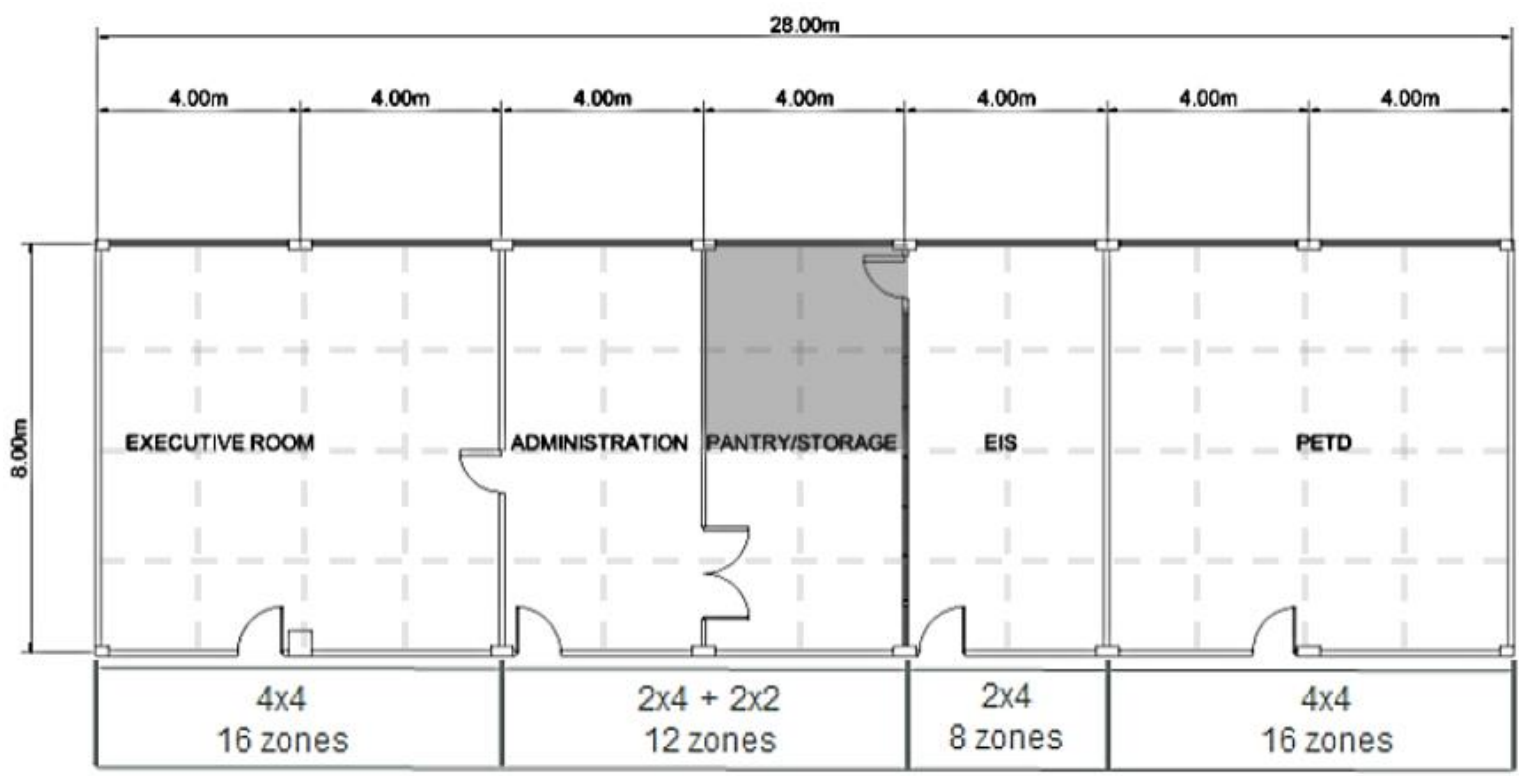

Figure 2. Zone partitioning for offices

For the project, the duration of the energy audit conducted was five (5) days within the first two weeks of May, during the summer season. Data was collected on an hourly basis between the operating hours of $8 \mathrm{am}$ to $5 \mathrm{pm}$. With this, the data would mainly reflect these conditions and the estimated energy consumption will come from these. Aside from this, the academic office building runs on a single meter, thus an electric bill breakdown of $\mathrm{kWh}$ consumption per office would not be obtained.

The work procedure for this study was being formulated while targeting two parameters; the specified EEIs of air conditioning units at desired room temperature and the desired lighting levels, respectively. In other studies, the EEI would usually be expressed in terms of $\mathrm{kWh} / \mathrm{sqm}$ [8], however the energy efficiency in terms of desired temperature and lighting levels were mainly analysed to target the ergonomic temperatures and lux levels and to focus on energy efficiency with respect to correct delivery of service by equipment. The temperature and lux levels are based on recommended ergonomic conditions for the type of facility expressed in terms of $\mathrm{kWh} / 24^{\circ} \mathrm{C}$ and $\mathrm{kWh} / 300$ lux, respectively, taking into account the ideal te mperature and lighting level standards for office workplaces.

To determine the EEI of the offices, the $\mathrm{kWh}$ consumption per output was calculated depending on the type of equipment. For the luminescence, the units were in $\mathrm{kWh} / \mathrm{lux}$ while for the temperature, these were expressed in $\mathrm{kWh} /{ }^{\circ} \mathrm{C}$ for all offices. The EEIs were obtained on a per-day basis, averaging the lux and temperature values of the partitioned zones and subjecting these with the daily $\mathrm{kWh}$ consumption of the lighting fixtures and ACUs. 


\section{Results and Discussion}

\section{Data Analysis}

From the initial meeting and ocular inspection of the offices, the proponents noticed that there were lighting fixtures blocked by shelves. Aside from this, the lightbulbs in some of the offices were observed to be broken, thus contributing to the dim atmosphere during the study period. In terms of blinds, the use of such varies per office, depending on the user's preference, however the additional load from solar hear gain should be taken into account when increasing visible transmittance from daylight use. Similar to the lighting fixtures, there are cabinets which obstruct the airflow of the ACU in the offices. For office equipment and desks that are located within the airflow path of the ACU, the louver would be placed upwards to remedy such. Given that the Administration Office and Executive Director's Office are connected, one (1) window type ACU was observed to be continuously in use for both rooms, thus its compressor could be overworked. This ACU however is located in the Administration Office. For the plug-in loads, the equipment most in use would be the desktop computers.

\section{Energy Efficiency Index for Lighting and Temperature}

After the energy audit procedure, the following EEIs per office were obtained as shown in Table 2 below. From the values, the office that required the most energy to achieve the appropriate working condition standards was the BRS for both lighting and temperature. The aged lighting and ACUs can contribute to such results.

Table 2. Offices and Their Corresponding EEIs (Lighting and Temperature)

\begin{tabular}{ccc}
\hline Office & $\begin{array}{c}\text { Lighting EEI } \\
(\mathbf{k W h} / \mathbf{3 0 0} \mathbf{l u x})\end{array}$ & $\begin{array}{c}\text { Temperature EEI } \\
\left(\mathbf{k W h} / \mathbf{2 4} \mathbf{C}^{\circ} \mathbf{)}\right.\end{array}$ \\
\hline Administration Office & 6.787 & 17.76 \\
BRS & 22.41 & 58.10 \\
EIS & 3.333 & 20.27 \\
Executive Office & 8.108 & - \\
Printing Office & 5.328 & 26.62 \\
PETD & 8.094 & 26.18 \\
PMO & 9.534 & 19.85 \\
UPAE & 13.90 & 27.12 \\
\hline
\end{tabular}

Comparing the lux readings with the standard lighting for office spaces, all the rooms do not adhere to the minimum of 300 lux for workplaces, thus they consumed less energy than required. Offices with the highest luminescence were the PETD, EIS, and Printing with values between 200-250 lux and an average daily energy consumption of 4.248 $\mathrm{kWh}$. Areas with the lowest average luminescence were the Executive Director's and PMO with below 100 lux and an average daily power usage of $2.754 \mathrm{kWh}$. Given that all these rooms were designed to be workplaces, the lack of proper lighting could possibly affect worker productivity.

As for the temperature, the EIS and PETD were able to reach the lower range acceptable value of around 24 Celsius, possibly due to the smaller room area and efficient ACU operation. The Executive Director's office has the highest temperature with around 27 Celsius, though this is due to the room relying on the unit of the Administration office for ventilation. The rest of the rooms range from 25 to 26 Celsius, and given that the energy audit was conducted during the summer season, these values are considered acceptable. 


\section{Energy Consumption of Offices}

From applying the established work procedure, the following energy consumption results were obtained per room as illustrated in Figure 3. Based on the graph, it is evident that the air conditioning units make up the majority of the energy consumption in almost all offices.

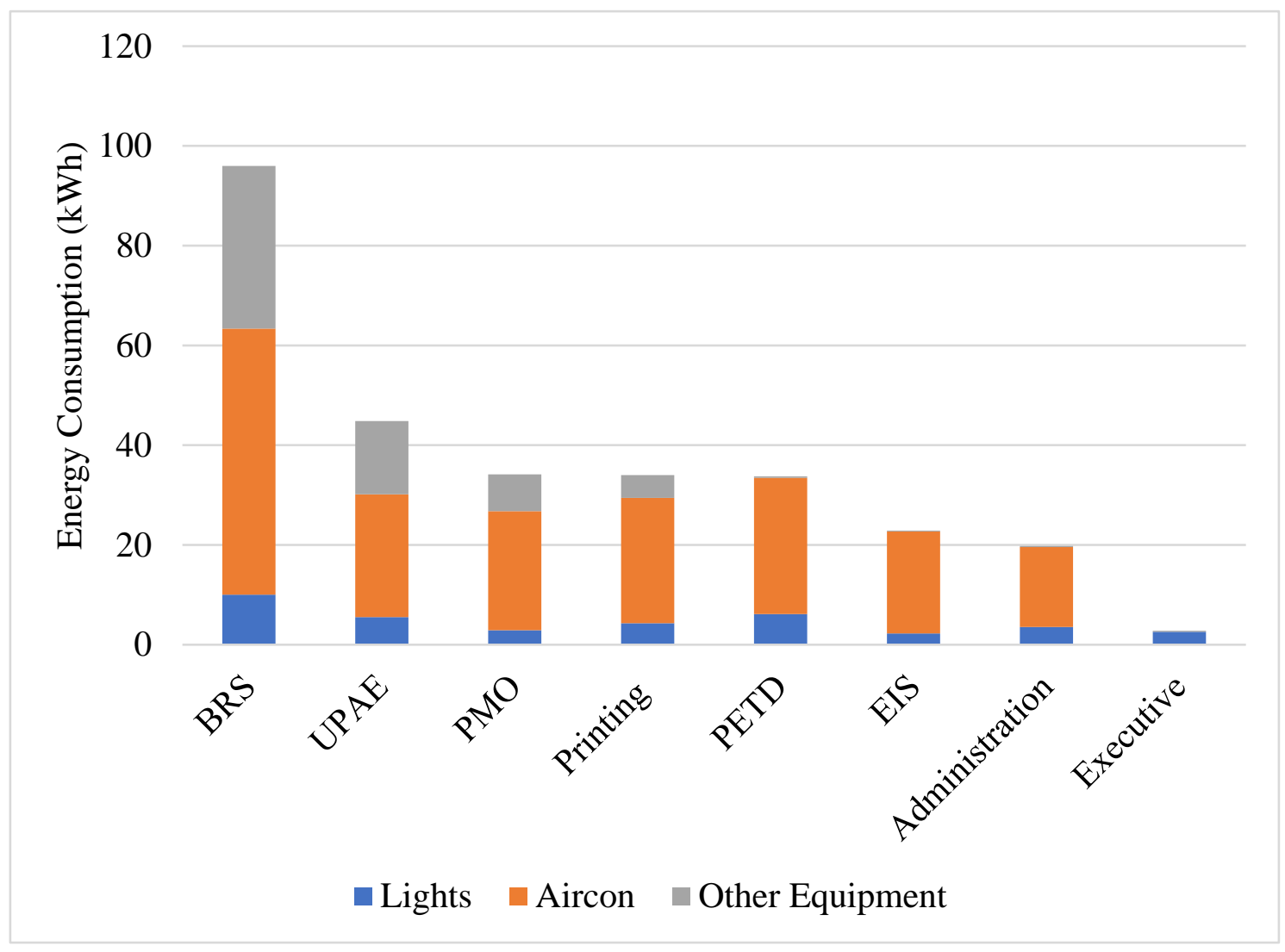

Figure 3. Daily energy consumption of offices $(\mathrm{kWh})$

Looking at the offices, the BRS is shown to consume the most electricity, particularly in its $\mathrm{A} / \mathrm{C}$ unit and the other equipment such as desktop computers. Factors such as the roughly 8 occupants that use the BRS office daily and that its aged A/C units are of the window type could contribute to its high energy consumption. In some of the rooms, the office equipment would use more power as compared to the lights, thus highlighting the low energy consumption of the lighting system. Areas such as the Printing Office, PMO, BRS, and UPAE have a higher $\mathrm{kWh}$ consumption for office equipment than lighting due to items such as large scale printers and copiers, desktop computer systems, and water dispensers/heaters. Note that the PMO is one of the offices with the lowest lux values measured during the audit.

Subjecting the energy consumption values to the corresponding office areas, the following energy use intensity (EUI) values were calculated as shown in Table 3. From the results, the Printing Office and BRS were shown to have the highest EUI values. Similar to the BRS, the Printing Office also has an aged window type ACU which consumes higher than its rated power. Given that the Printing also serves as the main office for printing materials of the academic building, its large scale printers are often being used. 
Table 3. Offices and Their Corresponding EUIs

\begin{tabular}{ccc}
\hline Office & $\begin{array}{c}\text { Area } \\
(\mathbf{s q m})\end{array}$ & $\begin{array}{c}\text { Energy Use Intensity } \\
(\mathbf{k W h} / \mathbf{s q m} / \mathbf{d a y})\end{array}$ \\
\hline Administration Office & 31.98 & 0.62 \\
BRS & 95.95 & 1.01 \\
EIS & 31.98 & 0.72 \\
Executive Office & 63.97 & 0.04 \\
Printing Office & 31.98 & 1.06 \\
PETD & 63.97 & 0.53 \\
PMO & 61.59 & 0.55 \\
UPAE & 95.95 & 0.47 \\
\hline
\end{tabular}

\section{Recommendations}

Given the EEIs for lighting and temperature, the following alternatives were illustrated below, which can serve as energy solutions for the offices.

\section{Lighting Design}

In all rooms, recommendations for the lighting design were given due to the lack of luminescence based on the given lighting standards for offices. These were classified into no cost and cost solutions. For the no cost, a rearrangement of the office layout to maximize luminescence within the workspace was suggested. Obstacles such as shelves and cabinets blocking the lighting fixtures were removed. For maximum lux values with minimal energy consumption, the use of LED lights is recommended despite the initial costs. There would be an average reduction of approximately $35 \%$ in energy consumption from the lights across all offices.

\section{Room Temperature}

For the ambient temperature, the no cost solution would also be to rearrange the office layout to remove obstacles that block the air flow of the ACU. Aside from this, a management procedure for the ACUs should be implemented, such as scheduling of ACU use and switching off the units after the offices' work hours. For office facilities wherein ACUs are usually used for extended periods of time each day (roughly 9 hours), the use of inverter technology is encouraged for long term energy savings. There would be an average reduction of roughly $38 \%$ in energy consumption across all offices. Along with this, cooling load calculations for the aforementioned facilities must be made to check if the ACUs are of the correct capacity. Another fixture change to consider would be the installation of solar films onto windows as a way to keep natural daylight and the outside view for worker productivity while reducing solar heat fenestration.

\section{Office Equipment}

Aside from conducting energy management for ACUs, it is recommended to extend this to the use of other office equipment. By simply unplugging devices not in use, the effects of phantom load in terms of power consumption can be avoided.

\section{Conclusions and Further Study}

From the collected energy audit data, the lighting levels across all offices studied were not able to meet standards of 300 lux, while for the temperature, the ACUs were able to reach values 
from 24-26 Celsius given the summer season. In terms of energy consumption, the ACUs were shown to use the most electricity for all rooms. Out of all the offices, the BRS would have the highest power usage based on the nominal energy consumption values, however from the EUIs, the Printing Office was also considered as a high electricity user. These can be attributed to the aged ACUs in the offices as well as the printer use, particularly in the Printing Office. Given the recommendations of energy savings alternatives such as installing LED lights, using inverter ACU technology, as well as proper energy management would improve energy efficiency within the academic university office building.

The results of this study can be utilized as a foundation to establish a national baseline for office enclosures in the Philippines. Aside from this, the energy audit procedure can be adopted in the current Philippine Energy Efficiency and Conservation Act of 2018. For future research, the building envelope performance of the academic university office building can be further studied.

An energy audit should be conducted when there are no occupants, thus before operating hours. Building simulation software can also be used to further examine the effects of building design, mechanical, and electrical systems in power consumption. Lastly, an error analysis may be carried out in conducting future energy audits using this methodology.

\section{References}

[1] M. Lister, Philippines Energy Efficiency and Conservation Action Plan 2016-2020 [Online]. Available: https://policy.asiapacificenergy.org/sites/default/files/philippines_energy_efficiency_actio n_plan2016-20.pdf [Accessed: January 2018]

[2] Chartered Institution of Building Services Engineers (CIBSE), CIBSE Recommended Lighting Levels, 2015 [Online]. Available: https://www.mountlighting.co.uk/cibserecomended-lighting-levels/ [Accessed: May 2017]

[3] American Society of Heating, Refrigerating, and Air Conditioning Engineers (ASHRAE), Thermal Environmental Conditions for Human Occupancy (Standard 55 - 2013), 2013 [Online]. Available: https://ashrae.iwrapper.com/ASHRAE_PREVIEW_ONLY_STANDARDS/STD_55_201 3 [Accessed: May 2017]

[4] M.A. Mohammed, and I.M. Budaiwi, "Strategies for reducing energy consumption in a student cafeteria in a hot-humid climate: A case study," Journal of Sustainable Development of Energy, Water and Environment Systems, Vol. 1, No. 1, pp. 14-26, 2013. doi: http://dx.doi.org/10.13044/j.sdewes.2013.01.0002

[5] F. Caram, M. Chan, M.A. Contreras, C. San Miguel, and M.A. Tamayao, "A system design study on the energy consumption patterns of the engineering library 1," Paper presented at $11^{\text {th }}$ Regional Conference in Energy Engineering, Manila, Philippines, September 2018.

[6] G. Stankevica, and A. Kreslins, "Impact of indoor climate on energy efficiency and productivity in office buildings," Paper presented at $7^{\text {th }}$ International Cold Climate HVAC Conference, Calgary, Alberta, Canada, 2012.

[7] C. Turhan, and G.G. Akkurt, "Assessment of thermal comfort preferences in mediterranean climate: A university office building case," Thermal Science, Vol. 22, No. 5, pp. 21772187, 2018. http://dx.doi.org/10.2298/TSCI171231267T

[8] Anisah, I. Inyati, F.X.N. Soelami, and R. Triyogo, "Identification of existing office buildings potential to become green buildings in energy efficiency aspect," Procedia Engineering, Vol. 170, pp. 320-324, 2017. https://doi.org/10.1016/j.proeng.2017.03.040 